\title{
STRENGTHS, WEAKNESSES, OPPORTUNITIES AND THREATS FOR USING REUSABLE LEARNING OBJECTS IN EUROPEAN HEALTHCARE CURRICULA TO ENHANCE CULTURAL SENSITIVITY
}

\author{
M. Brown, M. Taylor, C. Hall, S. Th. Konstantinidis \\ University of Nottingham (UNITED KINGDOM)
}

\begin{abstract}
Health care is becoming increasingly culturally diverse and there is a growing need for nurses to deliver culturally competent care patient centred care. Therefore, it is imperative that nurses are equipped with an awareness of what it means to possess cultural sensitivity. Internationally competent nurses need an awareness of cultural issues that challenge their attitudes and beliefs to reflect multicultural professionalism. Culturally competent professionals play a critical role in reducing health disparities and improving patient outcomes. Because of the expanded emphasis of globalised healthcare and international health concerns, there is a need to develop undergraduate opportunities to develop cultural awareness through reflection and self-directed learning.

TransCoCon, an ERASMUS+ co-funded strategic partnership of five European higher education institutions, focuses upon enhancing cultural awareness and promotion of transcultural competence in the professional context of nursing and healthcare. The project is working towards implementation of 5 interactive multimedia Reusable Learning Objects (RLOs) providing an innovative method of teaching for lifelong learning, which can be used for initial nurse education and continuing professional development through an on the spot agile reliable assessment through reflection on and within practice. However, there is little evidence on identifying the strengths, weaknesses, opportunities and threats for using reusable learning objects in European healthcare curricula and continuous professional development in order to enhance transcultural sensitivity.
\end{abstract}

In this paper, we conducted a qualitative SWOT analysis, based on expert's opinions from 5 different countries, revealing promising expectations for the use of the reusable learning objects in their healthcare curricula, but also identifying possible areas of attention.

The SWOT analysis conducted as a workshop within a TransCoCon training event. Participants were academics from five different institutions from Germany, Portugal, Ireland, Belgium and UK. Participants were asked to collaborative decide for the most important items in each category. They produced a list of prioritised items for each SWOT category, when consensus in each category was reached.

The SWOT analysis revealed that the use of reusable learning objects considered as an innovative way of teaching, which can include interactive elements to depict real life scenarios. They can accommodate different learning styles, while motivation of the students to be engaged could be higher by their use. Each reusable learning object aims for the learners to achieve one learning objective through it. This might be identified as a weakness, if it is not used within the appropriate context, and might lead to superficial learning. Opportunities arises for a modern healthcare curriculum encompassing new teaching methods using the reusable learning objects and inclusion in courses preparing healthcare students for international mobility pointed out. On the other side, participants identified the use of technology as a potential threat, especially to academics that are not aware of the benefits of the use of reusable learning objects as blended learning into the curriculum.

Keywords: Reusable learning objects, strengths, weaknesses, opportunities, threats, Cultural sensitivity. 


\section{INTRODUCTION}

Health care is becoming increasingly culturally diverse and there is a growing need for nurses to deliver culturally competent care. Therefore, it is imperative that nurses are equipped with an awareness of what it means to possess cultural sensitivity that meets the needs of individual patients/clients. Culturally competent professionals play a critical role in reducing health disparities and improving patient outcomes. Because of the expanded emphasis of globalised healthcare and international health concerns, there is a need to develop undergraduate opportunities to develop cultural sensitivity through reflection and self-directed learning.

Open Education resources have a central role in Healthcare education. A variety of e-resources exist like Virtual Patients, Reusable learning Objects, e-compendiums, MOOCs just to name a few [1]-[4].

Developing multimedia learning for trans-cultural collaboration and competence in nursing (TransCoCon ), an Erasmus + co-funded strategic partnership of five European higher education institutions, focuses upon enhancing cultural awareness and promotion of transcultural competence in the professional context of nursing and healthcare [5]. The project is working towards implementation of 5 interactive multimedia reusable learning objects (RLO's) providing an innovative method of teaching for lifelong learning, which can be used for initial nurse education and continuing professional development through an on the spot agile reliable assessment through reflection on and within practice. However, there is little evidence on identifying the strengths, weaknesses, opportunities and threats for using reusable learning objects in European healthcare curricula and continuous professional development in order to enhance transcultural competences.

As outputs from the project will be web based and published freely as open education resources for all, they will have a global use and benefit, with the sustainability of significant re-use by healthcare professionals.

After much intense discussion with our partnership meetings, discussion about terms and language differences, it has been agreed that content of the RLO's will follow the patient journey highlighting individual patient care within the context of culture and diversity. In order to achieve this, information needs to be useful, realistic, empowering for the learner to reflect on practice enabling individuals to make a difference to patient care [5].

Development of the resource has been challenging for all partners. We brought together nurse educators and student nurses from across our HE institutions bringing together inspirational innovative ideas to take our work forward. This process allowed us an opportunity to reflect and consider the context of cultural person centred care whilst considering the strengths and weaknesses of both the project outcomes and understanding enabling attitudinal change to culture and person centred care.

Reusable learning objects are self-contained user-friendly bits of information, which address practical cultural concerns and highlight best professional practice. Each resource represents between 5-15 minutes of learning and focusses upon the addressing a single learning goal, which may be used many times and in different settings [6]. RLOs have been widely used in healthcare education [7], meeting a variety of learning outcomes in nursing, midwifery, pharmacy, and many other educational programmes [8], [9]. A participatory design is followed engaging the relevant stakeholders, aka the potential learners and expert, following the Community of Practice principles [10], [11].

In this paper, we conducted a qualitative SWOT analysis, based on expert opinions from 5 different countries, revealing promising expectations for the use of the reusable learning objects in their healthcare curricula, but also identifying possible areas of attention. The remainder of the paper is structure $d$ as follows. Initially we discuss the methodology we used in order to contact our qualitative SWOT analysis, followed by a presentation of results. Next, we discuss the findings in relation with current literature, followed by a short conclusion in the form of a take home message.

\section{METHODOLOGY}

The SWOT analysis conducted as a workshop within a TransCoCon training event. Participants were recruited form this event. They were all academics in higher education from five different institutions from Germany, Portugal, Ireland, Belgium and UK. The duration of the workshop was about two hours. Twelve participants contributed to the study and the language used was English, in which all the participant were fluent. 
Initially, participants asked to individually note down the strengths opportunities, weaknesses and threats for using reusable learning objects into the healthcare curriculum in order to enhance transcultural competences to healthcare students and professionals. Next each participant asked to prioritise her choices with the most important to be first in her individual list.

Next, participants were asked to list all their choices for each of the categories (strength, weaknesses, opportunities, threats) in different tables, and collaborative decide for the most important items in each category. The following task that participants asked to do, was to prioritise each of the categories with the most important listed first. An iterative process of listing the items on each category was followed and consensus was reached in each category through discussion.

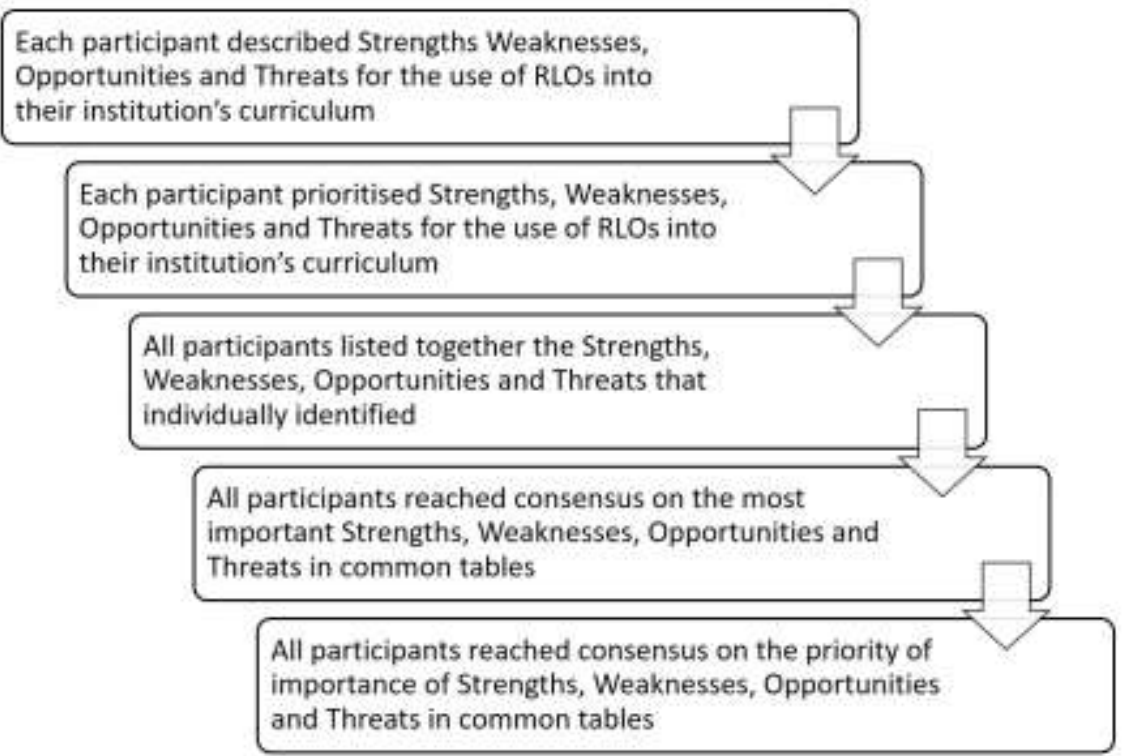

Figure 1. Study phases.

\section{RESULTS}

The strengths for using reusable learning objects into the healthcare curriculum in order to enhance transcultural competences to healthcare students and professionals as prioritized by the participants are listed in table 1.

Table 1. List of Strengths for the use of RLO as identified collaboratively by the participants

\begin{tabular}{l|l}
\hline \hline & \multicolumn{1}{|c}{ Strengths } \\
\hline 1 & Innovative ways of teaching - authentic and real \\
\hline 2 & Accommodates differences - learning styles (Aural, Oral and visual) \\
\hline 3 & Accommodates inclusive learning \\
\hline 5 & Opportunity to motivate the learner to engage in cultural sensitivity \\
\hline 6 & Opportunity to reflect on cultural knowledge \\
\hline 7 & Uses English (language of science) as well as partner languages \\
\hline 8 & Exposes learner to linguistic nuances \\
\hline 9 & Built on theory, Evidence Based Practice \\
\hline \hline
\end{tabular}


The opportunities for using reusable learning objects into the healthcare curriculum in order to enhance transcultural competences to healthcare students and professionals as prioritized by the participants are listed in table 2.

Table 2. List of Weaknesses for the use of RLO as identified collaboratively by the participants

\begin{tabular}{l|l}
\hline \hline & \multicolumn{1}{|c}{ Opportunities } \\
\hline 1 & Modern initiative, teaching methodology \\
\hline 2 & Can be used as part of a module or standalone teaching package \\
\hline 3 & Promotion of universities profile \\
\hline 4 & Promotion of learning \\
\hline 5 & Equality for all learners \\
\hline 6 & $\begin{array}{l}\text { Opportunity for }- \text { Attitudinal change, Building resilience, building } \\
\text { cultural sensitivity and cultural competence }\end{array}$ \\
\hline 7 & Opportunity to use as preparation for international mobility \\
\hline 8 & $\begin{array}{l}\text { Opportunity to combine the 5 RLO's into suite of recourses with } \\
\text { teaching and learning background reading }\end{array}$ \\
\hline \hline
\end{tabular}

The weaknesses for using reusable learning objects into the healthcare curriculum in order to enhance transcultural competences to healthcare students and professionals as prioritized by the participants are listed in table 3.

Table 3. List of Weaknesses for the use of RLO as identified collaboratively by the participants

\begin{tabular}{l|l}
\hline \hline & \multicolumn{1}{|c}{ Weaknesses } \\
\hline 1 & Singular goal, one aspect of reality, nursing situations are complex \\
\hline 2 & Lack of lecturer Involvement which can lead to superficial learning \\
\hline 3 & Lack of assurance that skills are developed \\
\hline 4 & Lack of interaction with tutors or learner to learner contact \\
\hline 5 & Learner need motivation to engage with RLO \\
\hline 6 & English language could limit understanding \\
\hline 7 & Need access to broadband, internet \\
\hline 9 & Possibility of information becoming dated \\
\hline \hline
\end{tabular}

The Threats for using reusable learning objects into the healthcare curriculum in order to enhance transcultural competences to healthcare students and professionals as prioritized by the participants are listed in table 3. 
Table 3. List of Threats for the use of RLO as identified collaboratively by the participants

\begin{tabular}{l|l}
\hline \hline & \multicolumn{1}{c}{ Threats } \\
\hline 1 & Too much technology, platforms and multimedia (overwhelming) \\
\hline 2 & $\begin{array}{l}\text { Resources - money, human, time - RLO may not be usable because } \\
\text { of time constraints or lack of knowledge }\end{array}$ \\
\hline 3 & $\begin{array}{l}\text { People not involve in development may not see the reverence/belief } \\
\text { in RLO }\end{array}$ \\
\hline 4 & Resistance to change \\
\hline 5 & $\begin{array}{l}\text { Interpretation of the assessment could lead learner to think they have } \\
\text { gained knowledge or already have the knowledge }\end{array}$ \\
\hline 7 & Lack of learner awareness of context of content \\
\hline 8 & $\begin{array}{l}\text { Risk of RLO not being used at all or continuously could make the RLO } \\
\text { extinct }\end{array}$ \\
\hline 9 & Lecturers may use it in isolation and not as part of a teaching package \\
\hline 10 & Lack of marketing the RLO \\
\hline \hline
\end{tabular}

\section{DISCUSSION}

\subsection{Strengths}

One of the strengths that the participants identified is that the RLOs accommodate different learning styles (Aural, Oral and Visual), while they include elements to address people with different needs, accommodating also inclusive learning [12], [13] as the participants of the study noted. Participants acknowledged the use of RLOs into the healthcare curriculum in order to enhance transcultural competences to healthcare students and professionals as an innovative way of teaching, which is "authentic and real". Despite the fact that e-resources are wide spread, the inclusion into healthcare curricula is not always the one that it is expected.

RLOs as an online tool is attractive to learners as it is accessible 24/7 providing interactive learning [14]. RLOs encompass many factors within the 3 categories identified by Pegler [14] resulting to the classic two factor theory of motivation by Herzberg [15], leading to learners engagement with cultural sensitivity.

The participants have the feeling that the RLOs were feeling professional, which might resulted from a two step review process, which enhance the quality of the resource and recognise the creators work [16].

Using English as language identified by the participants both as strength and as a weakness. Furthermore, there are some studies showing that learners might struggle to understand linguistic nuances [17], [18], since they are not professional in English. The participants believed that exposing the learner to linguistic nuances that exist within the RLOs is of his benefit to enhance her linguistic skills, which supported by [19].

RLOs are building on existing evidence and theories including of social constructivism [20], which is widely adopted nowadays. Furthermore, individual potential learner opinion is recognised and integrated following the Community of Practice [10], [11]. The use of such theories have been seen as a strength from the participants. 
One of the RLO strengths considered, is its openness to everyone. RLOs being open education resources (OER) have great impact, not only higher education, but also to healthcare professionals and the general public, including patients [21]-[25].

Each of the RLOs contains some assessment elements, which the participants believe that promotes retention and transfer of knowledge. Self-assessment considers to be very important for the self-directed learning process [26], while having the form of a reflection is of high value [27] and is widely used in healthcare education [28]. That gives also the possibility to reflect on cultural knowledge, as participants emphasised.

\subsection{Opportunities}

Having a modern initiative such as RLOs can lead to use of teaching methodologies, such as blended learning to enhance transcultural competences to healthcare students and professionals. Blended learning allows the participant to acquire deeper knowledge, as they can combine self-study time, with debriefing, conversations and reflections [2], [29]-[31]. RLOs can play an important role, both as prereading and post-reading, but also as an explanatory tool for difficult concepts.

The reusability of the RLO was acknowledged by the participants for its integration abilities in multiple contexts, either as standalone or as part of a teaching package. Simultaneously the participants noted also the possible threats that may arise from a non-experienced tutor or from resistance to change.

They also acknowledged that the RLOs into the healthcare curriculum is an opportunity to enhance transcultural competences to healthcare students and professionals, since they can promote University's profile by their impact as happened in the case of University of Nottingham [23], [25]. At the same time though they see it as an opportunity to promote learning to a wider audience providing access to high quality resources foster the equality between learners [13], [32].

RLOs has been seen as an opportunity to change attitudinal, Build resilience, build cultural sensitivity and cultural competences following the example of McAllister et al [33]. As student need to prepare for international mobility, RLOs are seen by the participants as good opportunity to be used in this scope [34], [35], having all the 5 RLOs that will be produced within TransCoCon ERASMUS+ project embedded in a learning package with other resources.

\subsection{Weaknesses}

RLOs specific educational goal, or not having enough information considered from the participants as potential weakness to include the RLO into the curriculum in order to enhance transcultural competences to healthcare students and professionals, justifying that nursing situations are complex. The power of RLOs though is the reusability element [36], and the transferability in different contexts, while a larger educational resource, will need adaptation that might lead to extra cost and time [37]. The participants also felt that this is also a strength of the RLOs.

The absence of human presence, either being a tutor or another learner when going through an RLO can be seen as a weakness that might lead to superficial learning by the participants. Self-directed learning though has many advantages [6], [38], [39] and used a lot in undergraduate and postgraduate healthcare, as well as in continues professional development. The participants noted also that there might be lack of assurance that skills are developed, however multiple studies have evidenced that RLOs contribute to skills development.

Similarly with some potential threats the participants believed that the learner might need motivation to engage with the RLO. The learners are responsible to be engaged with a learning resource using their own judge [38], [40], [41].

As less important weaknesses, use of English language and access to internet were mentioned. It should be noted that RLOs are developed in multiple language, but the majority of them are in English language.

Last but not least a weakness that listed with less importance in comparison to the others, that the information that the RLO might become dated, might be the reason behind threats such as resistance of change, interpretation of the assessment could lead learner to think they have gained knowledge or already have the knowledge; and weaknesses such as lack of assurance that skills are developed. 


\subsection{Threats}

The participants identified that technology might be overwhelming if it's a lot, when using reusable learning objects into the healthcare curriculum in order to enhance transcultural competences to healthcare students and professionals. Cognitive overload is indeed an issue that discussed a lot in literature [42]-[44], while methods and techniques to balance the existence of interactive elements in educational resources have been proposed, that are followed by TransCoCon's reusable learning objects [5].

Non-use of reusable learning objects might be for multiple reasons, including quality level, discoverability [45], luck of understanding, overvalued expectations. A number of Threats that participants identified are around the non-use of RLOs. Within TransCoCon project a number of actions have been taken in order to minimise that risk. A participatory workshop[8] with the learners is made for each RLO in order to ensure the acceptability by the target group [10], [11], while discoverability will be achieved listing them in the HELM Open (https://www.nottingham.ac.uk/helmopen/) and the ERASMUS+ portal, releasing them under a Creative Common licence.

Exaggerating expectations or luck of understanding is a problem that the non-mature learners might came across. As the RLOs built for one specific learning goal, the bid of information provided might need some predefined knowledge. Then is in the responsibility of the adult learner to be able to judge [38], [40], [41] what they should follow. On the other side is the responsibility of tutors and instructional designers to design courses that include RLOs in the right place fulfilling specific learning objectives.

Participants felt that "Resistance to change" might be a threat for the use of RLO's into the curriculum. It is well evident that individuals and organisation resist change [46], [47]. As Ullrich [48] noted lack of information about the change, unclear messages, and expectations resistance are among the main issues that influence the resistance to change.

An important aspect that the authors believe that it didn't arouse is the lack of digital literacy for the learners [49], but that can be easily explained from the nature of the RLOs, which are accessible through any device and any browser as a website [50].

\section{CONCLUSION}

The SWOT analysis revealed that the use of reusable learning objects considered as an innovative way of teaching, which can include interactive elements to depict real life scenarios. They can accommodate different learning styles, while motivation of the students to be engaged could be higher by their use. Each reusable learning object aims for the learners to achieve one learning objective through it. This might be identified as a weakness, if it is not used within the appropriate context, and might lead to superficial learning. Opportunities arises for a modern healthcare curriculum encompassing new teaching methods using the reusable learning objects and inclusion in courses preparing healthcare students for international mobility pointed out. On the other side, participants identified the use of technology as a potential threat, especially to academics that are not aware of the benefits of the use of reusable learning objects as blended learning into the curriculum.

\section{ACKNOWLEDGEMENTS}

Authors would like to thank all our partners for their valuable contribution to the TransCoCon project and the participants of this study. This work was supported by "TransCoCon: Developing Multimedia Learning for Transcultural Collaboration and Competence in Nursing", a project funded under the ERASMUS+ Programme, (GA No 2017-1-UK01-KA203-036612).

\section{REFERENCES}

[1] P. D. Bamidis et al., "An e-learning platform for aerospace medicine.," Hippokratia, vol. 12 Suppl 1, pp. 15-22, Aug. 2008.

[2] B. Foss, B. . Oftedal, and A. Løkken, "Rich media e-compendiums: A new tool for enhanced learning in higher education," Eur. J. Open, Distance E-Learning, vol. 16, no. 1, pp. 102-114, 2013.

[3] P. E. Antoniou, C. A. Athanasopoulou, E. Dafli, and P. D. Bamidis, "Exploring design requirements for repurposing dental virtual patients from the web to second life: A focus group 
study," J. Med. Internet Res., vol. 16, no. 6, p. e151, 2014.

[4] S. T. Konstantinidis et al., "The use of open source and Web2.0 in developing an integrated EHR and E-learning system for the Greek smoking cessation network," Stud. Health Technol. Inform., vol. 150, pp. 354-358, 2009.

[5] M. Brown, E. McSharry, S. Konstantinidis, and C. Hall, "Participation and partnerships in transnational open content development," in 12th International Technology, Education and Development Conference (INTED2018) Proceedings, 2018, pp. 8311-8318.

[6] R. J. Windle, D. McCormick, J. Dandrea, and H. Wharrad, "The characteristics of reusable learning objects that enhance learning: A case-study in health-science education," Br. J. Educ. Technol., vol. 42, no. 5, pp. 811-823, Sep. 2011.

[7] S. T. Konstantinidis, H. Wharrad, R. Windle, and P. D. Bamidis, "Semantic web, reusable learning objects, personal learning networks in health: Key pieces for digital health literacy," Stud. Health Technol. Inform., vol. 238, pp. 219-222, 2017.

[8] R. Windle and H. Wharrad, "Reusable learning objects in healthcare education," in Interprofessional e-learning and collaborative work: practices and technologies, A. Bromage, L. Clouder, J. Thistlethwaite, and F. Gordon, Eds. Hershey: IGI Global, 2010, pp. 244-259.

[9] M. Ferguson, M. Brandreth, W. Brassington, and H. Wharrad, "Information Retention and Overload in First-Time Hearing Aid Users: An Interactive Multimedia Educational Solution.," Am. J. Audiol., vol. 24, no. 3, pp. 329-332, Sep. 2015.

[10] J. Lave and E. Wenger, Situated learning: Legitimate peripheral participation. Cambridge, UK: Cambridge University Press., 1991.

[11] E. Wenger, "Communities of practice and social learning systems: The career of a concept," in Social Learning Systems and Communities of Practice, 2010.

[12] S. B. Navarro, P. Zervas, R. F. Gesa, and D. G. Sampson, "Developing Teachers' Competences for Designing Inclusive Learning Experiences," Journal of Educational Technology \& Society, vol. 19. International Forum of Educational Technology \& Society, pp. 17-27, 2016.

[13] G. Conole, "Fostering social inclusion through open educational resources (OER)," Distance Educ., vol. 33, no. 2, pp. 131-134, Aug. 2012.

[14] C. Pegler, "Herzberg, hygiene and the motivation to reuse: Towards a three-factor theory to explain motivation to share and use OER," J. Interact. Media Educ., 2012.

[15] F. Herzberg, "One more time: how do you motivate employees?," Harv. Bus. Rev., vol. 46, no. $1,1968$.

[16] R. Cafolla, "Project MERLOT: Bringing Peer Review to Web-Based Educational Resources," J. Technol. Teach. Educ., vol. 14, no. 2, pp. 313-323, Apr. 2006.

[17] T. M. Crea and M. McFarland, "Higher education for refugees: Lessons from a 4-year pilot project," Int. Rev. Educ., vol. 61, no. 2, pp. 235-245, Apr. 2015.

[18] B. Moser-Mercer, "MOOCs in fragile contexts," in European MOOCs Stakeholders Summit, 2014, pp. 114-121.

[19] C. Kinginger, "Enhancing language learning in study abroad," Annual Review of Applied Linguistics. 2011.

[20] L. Vygotsky, Mind in society: The development of higher psychological processes. Cambridge: Harvard University Press, 1978.

[21] T. Caswell, S. Henson, M. Jensen, and D. Wiley, "Open educational resources: Enabling universal education," Int. Rev. Res. Open Distance Learn., 2008.

[22] J. Hylén, "Open Educational Resources : Opportunities and Challenges," 2005.

[23] C. Redmond et al., "Using reusable learning objects (RLOs) in wound care education: Undergraduate student nurse's evaluation of their learning gain," Nurse Educ. Today, vol. 60, pp. 3-10, Feb. 2018.

[24] M. Ferguson, M. Brandreth, W. Brassington, P. Leighton, and H. Wharrad, "A Randomized 
Controlled Trial to Evaluate the Benefits of a Multimedia Educational Program for First-Time Hearing Aid Users," Ear Hear., vol. 37, no. 2, pp. 123-136, Mar. 2016.

[25] J. Williams, M. O'Connor, R. Windle, and H. J. Wharrad, "Using reusable learning objects (rlos) in injection skills teaching: Evaluations from multiple user types," Nurse Educ. Today, vol. 35, no. 12, pp. 1275-1282, 2015.

[26] J. W. Gikandi, D. Morrow, and N. E. Davis, "Online formative assessment in higher education: A review of the literature," Computers and Education. 2011.

[27] J. M. Sargeant, K. V. Mann, C. P. Van Der Vleuten, and J. F. Metsemakers, "Reflection: A link between receiving and using assessment feedback," Adv. Heal. Sci. Educ., 2009.

[28] K. Mann, J. Gordon, and A. MacLeod, "Reflection and reflective practice in health professions education: A systematic review," Adv. Heal. Sci. Educ., 2009.

[29] D. Chinarro, L. Bruton, and J. Bergues, "BLENDED LEARNING THROUGH PERVASIVE TECHNOLOGIES," in EDULEARN11: 3RD INTERNATIONAL CONFERENCE ON EDUCATION AND NEW LEARNING TECHNOLOGIES, 2011, pp. 6240-6248.

[30] K. Walsh, "Blended learning," BMJ, 2005.

[31] D. R. Garrison and H. Kanuka, "Blended learning: Uncovering its transformative potential in higher education," Internet High. Educ., 2004.

[32] M. Weller, B. de los Arcos, R. Farrow, B. Pitt, and P. McAndrew, "The Impact of OER on Teaching and Learning Practice," Open Prax., vol. 7, no. 4, pp. 351-361, 2015.

[33] G. McAllister and J. J. Irvine, "Cross Cultural Competency and Multicultural Teacher Education," Rev. Educ. Res., vol. 70, no. 1, pp. 3-24, 2000.

[34] B. F. Green, I. Johansson, M. Rosser, C. Tengnah, and J. Segrott, "Studying abroad: A multiple case study of nursing students' international experiences," Nurse Educ. Today, 2008.

[35] R. Clerehan, L. Mccall, L. Mckenna, and K. Alshahrani, "Saudi Arabian nurses' experiences of studying Masters degrees in Australia," Int. Nurs. Rev., 2012.

[36] R. J. Windle, H. Wharrad, D. McCormick, H. Laverty, and M. G. Taylor, "Sharing and reuse in OER: experiences gained from open reusable learning objects in health," J. Interact. Media Educ., vol. 2010, no. 1, p. 4, Dec. 2010.

[37] S. Wills and C. Pegler, "A deeper understanding of reuse: learning designs, activities, resources and their contexts," J. Interact. Media Educ., vol. 1, 2016.

[38] D. R. Garrison, "Critical Thinking and Self-Directed Learning in Adult Education: An Analysis of Responsibility and Control Issues," Adult Educ. Q., vol. 42, no. 136, pp. 136-147, 1992.

[39] L. Hammersley-Fletcher and P. Orsmond, "Reflecting on reflective practices within peer observation," Stud. High. Educ., vol. 30, no. 2, pp. 213-224, Apr. 2005.

[40] M. Knowles, The Adult Learner. A neglected species, 4th ed. Houston: Gulf Publishing, 1990.

[41] K. Cercone, "Characteristics of Adult Learners With Implications for Online Learning Design," AACE J., vol. 16, no. 2, pp. 137-159, Apr. 2008.

[42] S. Chang and K. Ley, "A learning strategy to compensate for cognitive overload in online learning: Learner use of printed online materials," J. Interact. Online Learn., 2006.

[43] C.-Y. Chen, S. Pedersen, and K. L. Murphy, "Learners' perceived information overload in online learning via computer-mediated communication," Res. Learn. Technol., vol. 19, no. 2, Jul. 2011.

[44] G. R. Bradford, "A relationship study of student satisfaction with learning online and cognitive load: Initial results," Internet High. Educ., vol. 14, no. 4, pp. 217-226, Sep. 2011.

[45] G. Brownfield and R. Oliver, "Factors influencing the discovery and reusability of digital resources for teaching and learning," ECU Publ. Pre. 2011, Jan. 2003.

[46] E. M. Rogers, Diffusion of Innovation, 5th ed. New York: The Free Press, 1995.

[47] P. Mungania, "E-learning in organizations: the process of transition and change," in UFHRD 2018, 2008. 
[48] M. Ullrich, "Making the move to online learning," in WebNet 98 World Conference of the WWW, Internet and Intranet Proceedings, 1998.

[49] E. M. Mamary and P. Charles, "On-site to on-line: Barriers to the use of computers for continuing education," J. Contin. Educ. Health Prof., vol. 20, no. 3, pp. 171-175, 2000.

[50] J. Williams, M. O'Connor, R. Windle, and H. J. Wharrad, "Using reusable learning objects (rlos) in injection skills teaching: Evaluations from multiple user types.," Nurse Educ. Today, vol. 35, no. 12, pp. 1275-82, Dec. 2015. 